\title{
La educación en la sociedad rural. Una evaluación cualitativa de la escuela rural catalana
}

\author{
Xavier Burrial \\ x.burrial@filcef.udl.cat \\ Universitat de Lleida \\ Teresa Sala \\ sala@pip.udl.cat \\ Universitat de Lleida \\ Lluís Samper \\ lluis.samper@geosoc.udl.cat \\ Universitat de Lleida \\ Teresa Torres-González \\ teresatorresgonzalez@geosoc.udl.cat \\ Universitat de Lleida
}

\section{Resum}

Des dels anys 90 del segle passat, l'escola rural espanyola, i la catalana en particular, s'ha convertit en un model d'escola que ha sabut superar el seu aïllament i gaudeix d'una apreciació positiva tant de pares com de docents. Els nous codis rurals/urbans que es conformen en l'actualitat donen significat a un nou estil de vida i l'escola rural s'ha transformat en una institució educativa amb un caràcter marcadament integrador que facilita el reconeixement d'una identitat pròpia i híbrida.

En aquest article ens ocupem primerament de la revisió teòrica que ens ofereixen autors clàssics, així com altres autors més contemporanis, sobre la concepció de la ruralitat; en segon lloc ens centrem en l'anàlisi detallada de les valoracions que fan els protagonistes socials de l'escola rural catalana.

El present estudi és la continuació d'altres investigacions sobre l'escola rural en les quals hem utilitzat metodologies qualitatives i quantitatives. Per tal d'optimitzar, contrastar i enriquir els resultats obtinguts en treballs d'investigació anteriors hem utilitzat un programa informàtic d'anàlisi semàntica de discursos: ATLAS.ti.

\section{Paraules-clau}

Escola rural, avaluació docent, món rural/món urbà, metodologia qualitativa, anàlisi de discursos.

\section{RESUMEN}

Desde los años 90 del pasado siglo, la escuela rural española, y la catalana en particular, se ha convertido en un modelo de escuela que ha sabido superar su aislamiento y goza de una apreciación positiva tanto de padres como de docentes. Los nuevos códigos rurales/urbanos que se conforman en la actualidad dan significado a un nuevo estilo de vida y la escuela rural se ha transformado en una institución educativa con un carácter marcadamente integrador que facilita el reconocimiento de una identidad propia e híbrida.

En este artículo nos ocupamos primeramente de la revisión teórica que nos ofrecen algunos autores clásicos, así como otros autores más contemporáneos, acerca de la concepción de la ruralidad; 
en segundo lugar nos centramos en el análisis pormenorizado de las valoraciones que realizan los protagonistas sociales de la escuela rural catalana.

El presente estudio es la continuación de otras investigaciones sobre la escuela rural en las que hemos utilizado metodologías cualitativas y cuantitativas. A fin de optimizar, contrastar y enriquecer los resultados obtenidos en trabajos de investigación anteriores hemos utilizado un programa informático de análisis semántico de discursos: ATLAS.ti.

\section{Palabras-clave}

Escuela rural, evaluación docente, vida rural/vida urbana, metodología cualitativa, análisis de discursos.

\section{REsumÉE}

Depuis les années 90 du siècle dernier, l'école rurale espagnole et l'école catalane en particulier sont devenues un modèle scolaire qui a surmonté son isolement et qui est apprécié à la fois par les parents et les enseignants. Les nouveaux codes ruraux/urbains actuels donnent un sens à un nouveau mode de vie et l'école rurale a été transformée en une institution éducative avec un caractère solide d'intégration qui facilite la reconnaissance de son identité hybride.

Dans cet article, nous abordons en premier lieu la révision théorique proposée par certains auteurs classiques, ainsi que par autres auteurs plus contemporains, sur la conception de la ruralité; deuxièmement, nous nous concentrons sur l'analyse détaillée des évaluations effectuées par les acteurs sociaux de l'école rurale catalane.

La présente étude est la suite d'autres recherches sur l'école rurale dans lesquelles nous avons utilisé des méthodologies qualitatives et quantitatives. Afin d'optimiser, d'opposer et d'enrichir les résultats obtenus lors de recherches antérieures, nous avons utilisé un logiciel informatique d'analyse sémantique des discours: ATLAS.ti

\section{MoTS-CLÉS}

École rurale, évaluation des enseignements, vie rurale /vie urbaine, méthodologie qualitative, analyse des discours.

\section{Abstract}

Since the 1990s, the Spanish rural school and the Catalan school, in particular, have become a school model that has overcome its isolation and it is appreciated by both parents and teachers. The current new rural/urban codes give meaning to a new way of life and the rural school has been transformed into an educational institution with a strong integration character that facilitates the recognition of its hybrid identity.

In this article, we first discuss the theoretical revision proposed by some classical authors, as well as other more contemporary ones on the conception of rurality; secondly, we focus on the detailed analysis of the evaluations carried out by the social actors of the Catalan rural school.

This study is a continuation of other rural school research in which we used qualitative and quantitative methodologies. In order to optimize, oppose and enrich the results obtained in our previous research, we used computer software for semantic analysis of speeches: ATLAS.ti 


\section{KEY WORDS}

Rural school, evaluation of teaching; rural life / urban life, qualitative methodology, discourse analysis.

\section{Introducción}

La evolución de la sociedad rural catalana así como la de su escuela, estuvieron marcadas por acontecimientos políticos y sociales de carácter mundial, nacional y regional desde finales del siglo XIX; hechos que se focalizaron en el período anterior y posterior de la Guerra Civil Española, la lucha de clases, el concepto de propiedad de la tierra y la miseria de la postguerra. No solamente en Cataluña, sino en todo el territorio español, las familias sobrevivieron acompañadas de la pobreza, del trabajo pesado y artesanal de la tierra y de la economía de subsistencia; las familias eran extensas y los recursos económicos y materiales escasos, de tal manera que las mujeres, los niños y los jóvenes debían ayudar durante largas jornadas en las labores del campo; así, la educación y la escuela no fueron contemplados como asuntos prioritarios, además tampoco estaban al alcance económico, ni físico de las familias rurales; cabe señalar, que la escuela de aquel contexto histórico y social, tampoco estaba al alcance de la mayoría de las familias en las ciudades, ocasionando que la sociedad española de ese período histórico alcanzara altísimas tasas de analfabetismo con respecto a otras naciones vecinas.

En el llamado período de la apertura económica y social de los años 50, España ingresa a diferentes instituciones internacionales, tanto de carácter cultural como económico, así ingresa en la Organización para la Cooperación y el Desarrollo Económico (OCDE), la Organización de las Naciones Unidas para la Educación, la Ciencia y la Cultura (UNESCO), la Organización para la Agricultura y la Alimentación (FAO), o la Organización Mundial de la Salud (OMS). La entrada del estado español al mercado internacional así como el restablecimiento de las relaciones exteriores, aunque retardada en comparación con otras naciones europeas, permite a la sociedad rural acercarse a la tecnificación de las infraestructuras de regadío y al uso de maquinaria agrícola, colocando al país en la era de la mecanización y la modernización cuya dinámica condujo a la transformación de la sociedad y las estructuras familiares, por ende también determinó la evolución de la educación y de la escuela que gracias a la recuperación económica pasaron a formar parte prioritaria de las familias; además la Ley General de Educación de 1970 con el decreto de la educación gratuita, universal y obligatoria hasta los 14 años, contribuyó al desarrollo del sistema educativo y la consolidación de las escuelas, tanto en el ámbito urbano como en el rural de todo el país. Cabe precisar que cada una de las regiones o comunidades así como las sociedades urbanas y rurales, y, a su vez la escuela, evolucionaron de manera diferente en el estado español dependiendo del tejido y la acción de variados factores, entre ellos el socioeconómico, el político, el cultural e incluso el geográfico.

En este artículo nos ocupamos primeramente de la revisión teórica que nos ofrecen algunos autores clásicos, así como otros autores más contemporáneos acerca de la concepción de la ruralidad desde la nostalgia del pasado y su evolución hacia la modernidad; en segundo lugar nos enfocamos en las valoraciones que realizan los protagonistas sociales de la escuela rural catalana.

Empujados por la llamada modernidad tardía, post-modernidad, modernidad líquida, como se le quiera llamar a nuestra historia moderna y dentro del consenso generalizado de crisis (Bauman 
y Bordoni, (2016: 80) la sociedad rural catalana modificó significativamente sus características estructurales y culturales a lo largo de las últimas décadas, con cambios en la estructura social (desagrarización, transformaciones demográficas, avances en los sistemas de comunicación...). De la misma manera las representaciones simbólicas (valores, ideologías, estilos y oportunidades de vida) se vieron alteradas; por ejemplo, las áreas rurales dejaron de ser percibidas negativamente (debido al recuerdo de pobreza y de trabajo duro en el pasado, además del éxodo masivo rural hacia las ciudades bajo la ideología de "abandonar el campo debido a su atraso social y económico"); para ser valoradas hoy día, como ámbito privilegiado en términos de bienestar personal, equilibrio ecológico e incluso idilio rural. No obstante, a nivel educativo no es incoherente que las investigaciones sobre la escolarización rural presenten poca o nula atención a los citados cambios sociales y culturales. Por citar un dilema habitual: el papel de la escuela rural como proveedora de los cambios sociales (incluso el riesgo de ser una herramienta aculturadora) o, por el contrario, ser garante de la continuidad de las tradiciones culturales.

En concreto: ¿Cómo es valorada la institución escolar catalana? ¿Cuáles son, a juicio de sus protagonistas, sus puntos fuertes y débiles? ¿Qué tipo de discursos legitiman las imágenes positivas y negativas de la escolarización rural en Cataluña?

En este artículo tratamos de responder a dos grandes objetivos específicos:

a. Explicitar el marco teórico del tema a partir de una revisión bibliográfica de la cuestión.

b. Analizar empíricamente las valoraciones que los respectivos actores sociales rurales pertenecientes a la sociedad catalana (docentes, familiares, expertos...) han elaborado a partir de la técnica de grupos de discusión (focus grups).

\section{Cambios en la relación entre sociedad rural y escuela}

\section{1. Imágenes de las nuevas ruralidades}

Explicar el concepto de lo rural desde las definiciones más sencillas y espontáneas, hasta aquellas más elaboradas y científicas, implica definir por defecto que lo rural suele ser aprehendido como lo opuesto a lo urbano; es decir lo rural es lo no industrial, lo rural es lo no desarrollado, pero además lo rural se asocia con las carencias del pasado... De ahí el predominio de estereotipos negativos asociados a la ruralidad desde el atraso a la ignorancia pasando por el caciquismo y la superstición.

La concepción de la ruralidad como antítesis de la modernidad, aunque hunde sus raíces en el pensamiento de la Ilustración, aparece legitimada en la obra de los primeros sociólogos como Comte, Marx o Spencer quienes más allá de sus profundas divisiones ideológicas, coinciden en defender una idea de progreso entendido como culminación de la civilización urbano-industrial. Incluso los que, como Tönnies o Weber, adoptaron una visión escéptica respecto al desarrollo urbano-industrial tendían a contraponer en términos dicotómicos la vida rural y la forma de vida urbana. (Entrena 1998: 80).

Las investigaciones realizadas por la sociología rural en las últimas décadas, destacan la complejidad y la diferencia del mundo social y las incompletas y parciales visiones de la ruralidad (Cloke y Little, 1997; Murdoch y Pratt, 1995). De manera que se parte de una idea diferente, lo rural no es un mundo aparte, sino una categoría socialmente construida. En concordancia con Díaz Méndez (2005) desde esta concepción ya no tiene sentido la dicotomía rural/urbano y la visión de un mundo rural condenado a la desaparición pierde sentido; por tanto se considera que una sociedad se 
crea en el proceso de interacción social, es un mundo además en un permanente proceso de cambio y creación. Las representaciones sociales que tenemos sobre la ruralidad o la urbanidad, así como las imágenes y las percepciones se conforman a partir de la interacción entre individuos de sociedades abiertas; es decir, es la sociedad actual quien construye mundos rurales o mundos urbanos, y/o mundos rurales/urbanos.

Cabe precisar, no obstante, que en la otra orilla del Atlántico, en los Estados Unidos, la influencia del pensamiento populista favoreció la institucionalización de una sociología rural con un enfoque "aplicado" (aversión a la teoría) y "positivo" (Newby y Sevilla Guzmán, 1983: 28). Fruto de esa tradición, el enfoque del continuum rural-urbano, vigente hasta los años sesenta del siglo pasado, manifestaba las idealizaciones de la ruralidad característicos de dicho pensamiento. Para ellos se trataba de mantener los valores jeffersonianos de la comunidad y la democracia asociados a la ruralidad tradicional. Por el contrario, se lamentaban de los "parásitos" y "ladrones" que controlaban el comercio, las finanzas y el aparato del Estado en perjuicio de los que "de verdad trabajaban y producían" (Entrena, 1998: 81). A partir de los cincuenta el progresivo declive del enfoque del continuum rural-urbano daría lugar, ya en las décadas de los sesenta y setenta, a las teorías de la modernización. Éstas, recuperando la tradición sociológica europea, adoptaron la perspectiva según la cual la ruralidad era considerada como un estadio social y económicamente atrasado, que era necesario recuperar, es decir modernizar. Vale la pena añadir que este nuevo enfoque coincide cronológicamente con lo que los especialistas han dado en denominar la Revolución Verde, esto es el espectacular incremento de la producción agraria, fruto tanto de la constante innovación tecnológica como del surgimiento de un sistema agroindustrial con el soporte de las políticas públicas y la influencia de las grandes corporaciones.

Hacia los años ochenta las apelaciones al reencuentro con la naturaleza, a la armonía con el entorno, a la calidad de vida y el respeto del medio ambiente manifestadas a través de las nuevas imágenes de la ruralidad evidencian la crisis de la idea de progreso continuo y sin límites que alentara los procesos de urbanización, industrialización y modernización durante el siglo XIX y gran parte del XX (Entrena, 1998: 82). Es en este contexto de re-significación de lo rural en el que cabe situar la noción de idilio rural:

the term has been used to describe the positive images surrounding many aspects of the rural lifestyle, community and landscape reinforcing at its simplest healthy, peacefull secure and prosperous representations of rurality. (Little y Austin, 1996: 101).

Un aspecto inicial de esta mitificación de la vida rural es la nostalgia del pasado y una huida de la modernidad. Como indican Little y Austin (1996) estos mitos asocian la ruralidad a una sociedad sencilla, inocente y genuina en la que los "valores tradicionales" persisten y la vida es más auténtica. Pero esta idealización que caracteriza al idilio rural no es neutral ya que posee un valor instrumental de soporte al patriarcalismo al incorporar, consciente e inconscientemente, importantes expectativas concernientes tanto al hogar como a la comunidad. En otras palabras, estas construcciones culturales de la ruralidad actúan como percepciones que modelan, de modo muy tangible, los patrones de conducta, los valores y las relaciones sociales. Los dos pilares ideológicos de tales percepciones idealizadas son la familia patriarcal y la comunidad tradicional.

Por otra parte, en su análisis crítico de las prácticas de crianza infantil en la actual Inglaterra rural, Matthews, et allii (2000: 151) subrayan como específico del idilio rural la aguda disyunción entre el simbolismo y las expectativas de la buena vida (lo emblemático) y las realidades y expectativas 
de crecer en comunidades pequeńas, remotas, fracturadas y escasamente dotadas de servicios (lo tangible). Esta misma distorsión ideológica ha sido documentada tanto en relación a temas de salud y calidad de vida (Watkins y Jacoby, 2007) como en relación, en este caso en Holanda, al mercado inmobiliario (Van Dam, Heinse y Elbersen, 2002). Conviene precisar, no obstante, que la literatura relativa al idilio rural coincide con sociedades altamente urbanizadas en las que, por contraste, la ruralidad está investida de un gran valor simbólico.

En el caso de Cataluña, diferentes autores (Estalella H. y Carrasco, 1998; Camarero, et. allii, 2009) han coincidido en atribuirle un modelo territorial líquido o difuso; una especie de macro ciudad difusa, en el que la ruralidad adquiere una gran relevancia cultural. Es decir que, en cierto modo, se dan las condiciones para encontrar manifestaciones de idilio rural.

\section{II.2 Evolución de la escuela rural catalana}

En concordancia con los estereotipos negativos de la ruralidad tradicional, la vieja escuela rural ha sido caracterizada como la cenicienta del sistema educativo. Su aislamiento geográfico, su carencia de material pedagógico, su pobre dotación en recursos humanos y materiales, su dependencia del caciquismo local... han sido percibidos como escollos insalvables para una calidad educativa. Acorde con los estereotipos de la ruralidad como un estadio sociocultural atrasado y subdesarrollado, su función era históricamente concebida en términos de aculturación, es decir de civilización de unos grupos sociales estigmatizados. En otras palabras, ha sido una "escuela misionera":

Au XIX siècle, l'école en France, comme dans la plupart des pays développés a été investie d'une mission civilisatrice. Elle doit fondre dans un modèle unique les particularismes propres aux différentes localités...

Le projet culturel de l'école se caractérise par sa visée universaliste et rationaliste: il affirme le primat du général sur le particulier, de la logique sur l'expérience, de la morale laïque sur les croyances particulières". (Duru-Bellat y Van Zanten, 1999: 91).

Los responsables de esta función "misionera" han sido, con toda la carga psicológica que comportaba tal empresa, los maestros y maestras rurales sometidos, sobre todo ellas y aún más si eran solteras, a un intenso escrutinio social: burguesas para los campesinos, campesinas para los urbanitas. Su rol de mediadores entre la población local y el mundo exterior, de legitimadores de la alta cultura pero defensora de las tradiciones vernáculas, les llevaban con frecuencia a quejarse de su soledad moral y afectiva. (Muel-Dreyfus, 1983).

En el contexto nacional francés, este modelo de escuela aculturadora se prolonga hasta aproximadamente los ańos cincuenta del siglo pasado, mientras que en el caso español debemos esperar, como poco, hasta el despliegue de la Ley General de Educación de 1970. Siguiendo a Soler (2005: 80) distinguiremos tres grandes etapas en la configuración de la actual escuela rural catalana:

\section{Primera etapa (1970-79)}

Caracterizada por el impacto de la Ley Villar Palasí ${ }^{1}$ de 1970 (concentraciones y cierres escolares) y que se prolonga hasta el Estatuto de Autonomía y primeras elecciones municipales democráticas.

1. Fue la Ley General de Educación promovida por el ministro Villar Palasi, que tuvo por novedad la gratuidad y obligatoriedad de la Enseńanza General Básica. 


\section{Segunda etapa (1980-89)}

En los ańos ochenta los traspasos de competencias educativas a la Generalitat, unidas a los movimientos de renovación pedagógica, favorecen un cambio del modelo de escuela rural. Es, a nuestro juicio, el momento decisivo y culmina con la creación de las ZER ${ }^{2}$ (zonas escolares rurales): Decreto 195/1988 de 27 de julio.

\section{Tercera etapa (1990-1998)}

El reconocimiento oficial a las quince primeras ZER, el impacto de la LOGSE³ (1990), así como las transformaciones del mundo rural ante los retos y perspectivas del cambio del siglo, el influjo de los procesos de globalización... dejan definitivamente atrás la imagen deteriorada de la vieja escuela rural. En un contexto en el que lo "rural" es una marca que está de moda, la escolarización rural empieza a ser considerada como un nuevo referente pedagógico.

La cuestión es ¿qué queda de rural en la "nueva" escuela rural? Para centrar el tema de nuestra investigación: en una época de crisis de la institución escolar ¿qué hace que la escolarización rural sea percibida mayoritariamente como positiva?, ¿cómo afecta el cambio en la evolución de la ruralidad a las funciones escolares?, ¿cómo viven sus principales actores (maestros, pero también familias, expertos, responsables, políticos...) tales transformaciones?, ¿qué ha cambiado de su estructura interna y de su relación con el nuevo entorno rural?

Para Boix (2003) en un mundo cada vez más desruralizado (en el sentido de que las actividades del sector primario de la economía pierden importancia) la nueva escuela rural se transforma en una institución educativa con un marcado carácter equitativo. En tanto que una escuela abierta a la comunidad, es una institución que parte de la propia realidad y posibilita la creación de "estructuras de conocimiento locales" como el punto de partida para la puesta en marcha de sus objetivos pedagógicos: participación social y promoción cultural del territorio.

Pero en un período histórico de inmensa globalización, no acaba de entenderse cuál pueda ser, en cada caso, la especificidad de las respectivas culturas locales. A título anecdótico: millones de nińos en distintos continentes comparten los mismos programas de dibujos animados, anuncios publicitarios, canciones, juguetes... El fenómeno de la "glocalización" —una combinación de la renovada importancia de las localidades en sincronía y estrecha relación con la pérdida de significación de la distancia espacial (Bauman y Bordoni 2016, 152) - ha erosionado, tal vez de modo irreversible, la vieja distinción entre cultura urbana y cultura rural. Por una parte, las normas y patrones de vida tienden a expandirse e hibridarse pero, por otra, las estructuras de significado de los diferentes grupos sociales que habitan el campo (entre los cuales los campesinos ya no son la mayoría) se han vuelto más dinámicas y complejas. Más allá de los imaginarios... ¿Qué queda hoy de la ruralidad tradicional?

Los estudios empíricos y las estadísticas actuales indican que debido a la crisis económica, hablemos sólo de España y de Cataluña en este momento, un porcentaje de ciudadanía urbana retorna a los pueblos en busca de bienestar social y económico no alcanzado en la ciudad; los discursos nos hablan de una "mejor calidad de vida", entre otros elementos positivos. ¿Podríamos entonces preguntarnos si la escuela rural se convierte en una oportunidad de acercamiento con lo

2. Agrupaciones en Cataluña de varias escuelas próximas entre ellas, cada una con entidad propia, pero que a la vez comparte un proyecto educativo con los otros centros.

3. Es una Ley Orgánica General del Sistema Educativo, promovida por el primer gobierno socialista, una de las características principales es partir de un currículum que permite a cada centro adaptarlo a su entorno. 
urbano? o ¿la escuela rural es una necesidad que la ciudad no logra cubrir? De la forma que fuere, la escuela rural es un espacio educativo vital donde los sujetos o los actores se encuentran y conforman una nueva sociedad facilitando la integración y el reconocimiento de una identidad propia e híbrida que conforman los nuevos códigos rurales/urbanos, y que en todo caso dan significado a un nuevo estilo de vida. La escuela rural, toma un sentido y rumbo diferente al que había mantenido hasta el momento y se transforma en una institución educativa con un carácter marcadamente integrador.

Según el criterio de Bustos (2009) en un contexto de transformación (el tránsito de la vieja ruralidad a nuevas realidades heterogéneas) la escuela se enfrenta al dilema de favorecer los cambios o quedar como fijadora de los rasgos definitorios de la tradición rural. Un segundo elemento de reflexión lo constituye el difícil equilibrio entre modernidad e identidad rural. Por último, la contraposición entre una creciente heterogeneidad estructural (diferencias demográficas, económicas, sociales... entre comunidades autónomas e incluso inter-comarcales dentro de una misma región) y la homogeneidad cultural derivada de las nuevas tecnologías informativas, así como de las mejoras en las comunicaciones que difuminan la distancia entre las formas de vida rural y urbana, al igual que muchas singularidades locales. En la imagen actual de lo rural desde una visión externa: “... se ha pasado de una valoración claramente negativa a otra positiva. Por un lado, se contrapone al malestar urbano extendido en las ciudades la calidad de vida de un medio rural más saludable, tranquilo, seguro y sociable. Por otro se subrayan los valores ecológicos intrínsecos de los espacios rurales" (Bustos 2009: 456).

Obviamente, todo ello repercute sobre la institución escolar. Los docentes deben encontrar el equilibrio entre el respeto a las tradiciones autóctonas y los retos de la nueva sociedad informacional. El modo en que se armonizan es una de sus mayores dificultades porque, entre otras razones, parten del convencimiento de que los cambios en el contexto son los responsables de las transformaciones escolares, y no a la inversa.

Recapitulando lo ya expuesto: debemos estudiar el binomio sociedad rural-escuela desde una perspectiva contextualizada tanto en términos históricos como geográficos. Por ejemplo, si, como ya hemos indicado, en un creciente número de sociedades europeas es pertinente hablar de "idilio rural", en otros territorios aún hoy permanece vigente la noción contrapuesta de "idilio urbano": la identificación del éxito vinculado a la ciudad frente al fracaso personal de aquellas personas que "tuvieron que quedarse en el pueblo" (Benito 2013: 57). Tal sería el caso de Castilla y León una de las regiones más extensas y despobladas del continente europeo, y donde, en términos de educación, una de cada tres centros escolares es una escuela rural, lo cual coincide con excelentes resultados en las evaluaciones educativas internacionales de la OCDE (pruebas PISA).

Pero en este marco geográfico, la escuela, paradójicamente gracias a su buen funcionamiento, sigue teniendo incidencia en la despoblación rural: como facilitadora de la "huída ilustrada" (sobre todo de mujeres) y como generadora de identidades urbano-céntricas (Benito 2013). Es decir que las repercusiones de las interrelaciones entre la escuela y sociedad rural pueden tener un efecto contrapuesto, según las especificidades demográficas, económicas, culturales, políticas... de cada territorio: idilio urbano vs. idilio rural, éxito académico vs. éxodo rural, urbano-centrismo vs. tradiciones locales.

Para finalizar, la relación entre la institución escolar y el contexto rural en la actualidad y en sociedades altamente urbanizadas tiende a ofrecer una imagen casi inversa a la de hace un siglo: de 
vector de los procesos de aculturación y mediocre valoración a santuario de las identidades locales y referente pedagógico.

\section{Valoraciones sobre la escuela rural catalana}

\section{III.1. Metodología}

El presente estudio es la continuación de otras investigaciones sobre la escuela rural en las que hemos utilizado metodologías cualitativas y cuantitativas. En primer lugar, en 2007, se realizaron cinco etnografías, entrevistando a maestros y directores y observando el entorno de centros situados en poblaciones muy diversas entre sí. Durante el curso 2007-08 se efectuó una encuesta, con preguntas pre codificadas y preguntas abiertas, a más de 200 escuelas elegidas al azar para obtener un perfil de los docentes y de los discentes, conocer el tipo de población en las que están situadas y saber cuáles son los puntos fuertes y débiles de la escuela rural. Esta misma encuesta se repitió durante el curso 2012-13, permitiendo así hacer una serie de comparaciones (Burrial, et allii 2007 y 2008). Así mismo, entre 2008 y 2010 se organizaron seis grupos de discusión cuyos discursos fueron objeto de un análisis semántico siguiendo el modelo de análisis crítico de Van Dijk (Sala et allii 2014). Finalmente, en este trabajo, hacemos un análisis de cuatro de estos discursos a partir del programa informático ATLAS.ti.

En el diseño de los seis grupos se tuvieron en cuenta los siguientes elementos: a) hábitat; b) división en estratificación social; c) división en género y edad, y d) división entre categorías socioeducativas: alumnos, padres y madres de alumnos, docentes, "expertos". A partir de los elementos anteriores, los grupos analizados fueron los siguientes:

"Amas de casa". Sesión realizada en una pequeña población (948 habitantes) geográficamente apartada.

"Población periurbana" (6.058 habitantes) cercana a la capital provincial de la que es casi "el barrio de las urbanizaciones".

"Maestros". Pequeño pueblo agrícola (un tercio de la población activa) de 1.356 habitantes, a orillas del río Segre y cercana a la capital provincial.

“Grupo Expertos”. Integraban el grupo siete personas que por su situación profesional o por su previa experiencia laboral pudieran ser consideradas expertas en el tema (algunos de los miembros ocupan o han ocupado cargos de responsabilidad política a nivel local o provincial).

La pregunta-provocación inicial para comenzar y orientar la discusión era: “¡están de acuerdo con la valoración positiva de la escuela rural?, ¿no es exagerada esta valoración positiva de la escolarización rural?" Previamente, en la presentación del equipo y del tema, habíamos resumido las conclusiones de nuestro primer estudio. En una segunda fase, después de que uno o varios de los miembros del grupo iniciaran su intervención, el animador focalizaba las intervenciones en las causas o motivos de tales valoraciones y en el relato de experiencias personales relativos en la escuela rural y su relación con la comunidad local.

En todos los casos se desarrolló una dinámica grupal muy activa y los diferentes miembros de los grupos discutieron larga y animadamente sobre el tema propuesto. De hecho, la duración de las sesiones sobrepasó en más de un caso el horario máximo previsto de 90 minutos. El trabajo de campo se realizó a lo largo de los cursos académicos 2008-09 y 2009-10. Por razones de seguridad, llevamos un doble registro de audio y de vídeo. 
A fin de optimizar, contrastar y enriquecer los resultados obtenidos en años anteriores con relación a este trabajo de investigación se decide utilizar el programa informático ATLAS.ti. A continuación describimos el procedimiento seguido con esta herramienta en esta nueva etapa de la investigación.

De acuerdo con Miles y Huberman (1994), una vez realizadas las transcripciones que surgen de cada uno de los grupos de discusión arriba mencionados, seguimos los pasos que sugieren estos autores: a) reducción de datos; b) organización y presentación de los resultados; c) interpretación y verificación. (Casasempere, 2011).

En tal sentido nos ceñimos al propósito analítico indicado para trabajar con ATLAS.ti: a) reducción de los datos: búsqueda y análisis de las ideas, temas e interpretaciones que tuviesen que ver con el propósito y objetivos de la investigación. Su operación consistió en colocar "códigos" en forma de marca o un símbolo que se aplicaron a frases o párrafos que nos ofrecieran significado al propósito y objetivos de la investigación. Para Taylor y Bogdan (1986) en la investigación cualitativa, la codificación es un modo sistemático de desarrollar y refinar las interpretaciones de los datos; en esta etapa de la investigación obtuvimos finalmente 91 códigos (entre ellos por destacar algunos: "escuela pequeña", "ser de pueblo", "tranquilidad", "gente del pueblo", "curriculum limitado", "clases reducidas", "cotidianidad", "una gran familia", etc.

Esta técnica de codificación que empleamos se denomina Codificación abierta, definida por Strauss y Corbin (2002) como el "procedimiento analítico por medio del cual se descubren los conceptos en términos de sus propiedades y dimensiones".

Un segundo nivel correspondió a la categorización; es decir, organizar en "familias" estos códigos. Esta categorización tuvo por objeto agrupar o clasificar conceptualmente este conjunto de elementos en forma de códigos, los cuales compartían significado; así pues estarían estos elementos cumpliendo ya un nivel más "conceptual" que a nivel de datos sin tratamiento. Como podemos observar la reducción de datos a través del ATLAS.ti nos condujo a la formación de "familias de códigos". En nuestro proceso obtuvimos 13 familias (entre ellas cabe destacar: "percepciones ideológicas", "valoraciones positivas", "identidad", "el pueblo", "el pasado", "valoraciones negativas".

Un tercer nivel nos condujo al proceso de Codificación axial, es decir "relacionar categorías (familias) con subcategorías siguiendo la línea de sus propiedades y sus dimensiones y observar "cómo se entrecruzan y vinculan". (Strauss y Corbin, 2002: 135). Este proceso nos ofreció visualizar en conjunto las relaciones formadas por las diferentes categorías y códigos a través de las redes (networks) o representaciones visuales que ofrece el software ATLAS.ti; de esta manera abarcamos el punto b) organización y presentación de los resultados, lo cual nos condujo a un nivel de abstracción superior mejorando la interpretación del fenómeno estudiado y por tanto dirigiéndonos a la conceptualización o realización constructo teorético tal como recomienda Casasempere (2011), pertinente y necesario para la elaboración de las conclusiones; en nuestro caso una nueva etapa de la investigación. Así finalmente conseguimos alcanzar el punto c) la interpretación y verificación de los resultados.

Cabe destacar que sin la experiencia y conocimiento profundo del tema estudiado por parte de los investigadores no sería posible bajo ningún concepto la realización del constructo teorético y menos de la realización de unas conclusiones de nivel empírico.

\section{III.2. Características generales}

Del análisis del cuadro de valoraciones positivas y del cuadro de valoraciones negativas generados por el programa ATLAS.ti, constatamos un predominio de las imágenes positivas sobre las negativas. 
Las valoraciones sobre la escuela rural están relacionadas con otras redes de valoraciones: percepciones ideológicas, sociedad y relaciones sociales, así como con la red identitaria. Estas valoraciones se refieren tanto a la imagen de la escuela como a las actividades docentes y a las relaciones con los grupos familiares.

Un aspecto relevante es la existencia de una cierta ambivalencia en las valoraciones puesto que un mismo código puede ser percibido como una ventaja o como un inconveniente.

\section{La imagen de la escuela}

En el esquema "Red de valoraciones positivas" del análisis realizado con ATLAS.ti, encontramos que tanto las $A M P A S^{4}$ como el pueblo valoran favorablemente la escuela rural.

En lo positivo, los discursos nos muestran una imagen de un "modelo de escuela pequeña", con "clases reducidas", de "proximidad", en la que sus miembros forman "una gran familia". Pero también se pone de manifiesto que existe un "déficit en infraestructuras".

\section{La docencia}

Las opiniones favorables referentes a la docencia que aparecen con más frecuencia en los grupos de discusión son: la "buena calidad de la docencia", "clases reducidas", "organizadas" y se señala la importancia de la "libertad", la "diversidad" o la enseńanza de "valores".

Detrás de estos códigos, en los discursos encontramos expresiones del tipo: "atención individualizada", "intervención personalizada", "ausencia de masificación", "baja ratio", "agrupamiento flexible", "agrupamiento que favorece el aprendizaje", "elevada y positiva interacción profesor/alumno", "currículo flexible y abierto", "utilización de metodologías didácticas activas y participativas", "clima de trabajo favorable", "autonomía del alumno", "responsabilidad" y "calidad de relaciones y de enseñanza".

La etiqueta "clases reducidas" es ambivalente, ya que aparece como valoración positiva, pero también como valoración negativa.

Los discursos también ponen de manifiesto algunos códigos que remiten a aspectos negativos, por ejemplo el "currículo limitado" o "nińos de diferentes edades con un solo profesor en el aula".

\section{Las familias}

Las familias valoran positivamente la "familiaridad" y la "tranquilidad", muestran su "satisfacción" con la escuela y a pesar de algunos inconvenientes, por ejemplo las "limitaciones en las actividades extraescolares", consideran que esta tipología escolar representa una "comodidad", siendo "motivo de satisfacción” y un "privilegio" tanto para los padres como para los hijos.

Constatamos, como ya lo hicimos a partir del análisis semántico-crítico, que estas valoraciones obtenidas con ATLAS.ti son coincidentes con las encuestas realizadas en 2013 y en 2007.

El análisis con ATLAS.ti proporciona una serie de códigos y mapas conceptuales que permiten observar de manera esquemática las relaciones que se establecen entre los diferentes conceptos, lo cual sería difícil de conseguir a partir de un análisis interpretativo y con la ventaja que para cada código se pueden consultar los verbatim que recogen el fragmento de discurso y de este modo contextualizar y precisar las opiniones expresadas. 


\section{Conclusiones}

La revisión bibliográfica confirma que a lo largo de las últimas décadas, el entorno rural ha experimentado importantes cambios sociales tanto en términos estructurales como culturales. Es decir, no sólo se han producido transformaciones económicas, demográficas, tecnológicas... sino que ello ha repercutido a nivel de las representaciones simbólicas, las identidades o el arraigo.

El pasado del mundo rural catalán y su poco desarrollo socioeconómico y cultural hasta hace unas pocas décadas atrás, alimentaron una sociedad llena de estereotipos que iban desde la superstición, el atraso, el caciquismo y la ignorancia; como es lógico analizar, su escuela y la calidad educativa no quedaron fuera de estos matices ideológicos si recordamos la imagen de su pasado: escuelas de difícil acceso, con enormes carencias pedagógicas y físicas, aunado a los pocos recursos humanos, sometidos además, a los intereses políticos del Estado y a las tradiciones vernáculas de la sociedad.

Debieron de pasar décadas para que la modernidad diera paso a la transformación estructural de la sociedad, la familia y de la escuela. A nivel institucional, la transformación de la escuela rural catalana no estuvo exenta del conflicto social enmarcado por los cierres de las escuelas y la lucha por el Estatuto de Autonomía. Van a ser, a partir del Decreto 195/1988 del 27 de julio, y el reconocimiento oficial de las primeras quince escuelas ZER, los factores determinantes para dejar en el pasado, a las deterioradas, no solamente por carencias pedagógicas e insuficiente dotación material, sino por la ideología de escuela rural atrasada.

El nuevo escenario de la globalización también ha cuestionado la realidad objetiva de la enseñanza en el mundo rural. La institución escolar no ha podido sustraerse a la aparición de estas nuevas ruralidades heterogéneas y dinámicas, y debe en consecuencia responder a nuevos retos. En contraste con la vocación aculturadora "misionera", de la vieja escuela rural las nuevas realidades educativas de los entornos rurales han experimentado una revalorización de sus funciones sociales.

Pero esta renovada buena imagen de la escuela rural no es incompatible con significativas diferencias sobre sus funciones sociales según el contexto en el que se ubican. La literatura especializada ofrece suficientes ejemplos de los efectos contrapuestos de las interrelaciones entre escuela y sociedad rural a partir de las características específicas (economía, demografía, marco político...) de cada territorio. Dicho en otras palabras: "idilio urbano" y éxodo rural vs. "idilio rural" y afianzamiento de la identidad local.

La cuestión clave que ha focalizado nuestro estudio empírico es ¿qué elementos discursivos subyacen en la valoración básicamente positiva de la escuela rural catalana? Mediante la metodología en base a la técnica de los grupos de discusión para la obtención de los datos, y por otra parte, la utilización de la herramienta ATLAS.ti para profundizar en su análisis, nuestro objetivo ha consistido en visualizar las valoraciones efectuadas por los sujetos de nuestra investigación.

En este análisis, la valoración que ofrecen nuestros entrevistados en torno a la actual escuela rural catalana, se enfoca desde la renovación pedagógica, lo positivo de lo ecológico, las ventajas del medio ambiente rural y la enseńanza de los valores tradicionales unidos a la preservación de la identidad. Los discursos de los diferentes actores delatan las transformaciones ideológicas que en un pasado reciente se definirían dentro de lo negativo y el atraso; esta ideología transformada, retrata a la actual escuela rural catalana más bien en tono de privilegio, escuela de clases reducidas, con ambiente de tranquilidad, familiaridad y cotidianidad; es decir, categorías que se enmarcan dentro de lo positivo colocando a la escuela rural catalana como referente pedagógico a nivel nacional y su entorno rural casi como algo idílico. 
La primera conclusión es que aunque predominantemente esta imagen "positiva" de la escuela rural catalana, no queda libre de ambivalencias. Por ejemplo, la categoría "clases reducidas" se puede percibir como un aspecto positivo que favorece el aprendizaje personalizado, pero también, desde el punto de vista de la socialización del alumno se manifiesta como un aspecto negativo.

En segundo lugar, estas valoraciones, tanto las frecuentes imágenes positivas como las escasas referencias negativas, son coincidentes con los datos de las previas encuestas; concretamente: atención personalizada al alumno, baja ratio de alumnado/profesorado y agrupamiento flexible (aulas multinivel).

Por último la utilización del ATLAS.ti en el procesamiento de los discursos nos autorizan a afirmar que existe una potente relación entre tres redes conceptuales: 1) las percepciones ideológicas (entre las que destacan códigos relacionados con el idilio rural como por ejemplo "una gran familia" y "orgullo de ser de pueblo"); 2) la red identitaria (especialmente identidades locales y de género que en la terminología de Castells (1998) corresponden a identidades de resistencia); y 3) las valoraciones positivas (como por ejemplo, "escuela pequeña", "clases reducidas", "atención personalizada" o "agrupamiento flexible").

En síntesis, la buena imagen de la escolarización rural en Cataluña se fundamenta tanto en códigos pedagógicos como en una revalorización de la ruralidad cercana a la teoría del idilio rural. Además también se han modificado los marcos conceptuales que describen, analizan y, sobre todo, interpretan estas nuevas realidades de la sociedad rural. Las nuevas perspectivas teóricas suponen un cuestionamiento de las concepciones clásicas de la ruralidad en la medida en que critican la visión esencialista y dualista de binomio rural-urbano. Por el contrario, lo que hoy predomina es el afirmar la naturaleza plural, compleja y dinámica de las nuevas ruralidades concebidas como categorías socialmente construidas. Frente a la visión dicotómica del conjunto rural-urbano se tiende a poner el énfasis, más allá de unas realidades objetivas en continua mutación, en las representaciones sociales tanto en la ruralidad como en la urbanidad, así como en la dimensión ideológica de tales imágenes.

¿Y cómo podemos explicar sociológicamente este cambio ideológico en tonos de negro a blanco, en torno a la escuela rural catalana y en tan pocas décadas? La explicación no es solamente en base a la transformación acelerada de las sociedades en los últimos tiempos; la razón también se encuentra en la globalización de la economía, en las sociedades de consumo, en las transformaciones demográficas, el alcance de los medios de comunicación y el avance tecnológico; es decir, los factores antes mencionados y la hibridación entre lo rural y lo urbano permite permanecer en el limbo del pasado y del presente, además la "glocalización" permite al hombre actual aspirar las comodidades que le ofrece el ambiente moderno y frío de la ciudad, pero también vive y necesita de la nostalgia de su pasado rural.

\section{Bibliografía}

ALABART, A.; VILÀ, G. (2007). “Territori i estructura social” En M. Montagut (coord.). Societat catalana. Barcelona, Associació Catalana de Sociología. pp. 177-202.

BAUMAN, Z. (2003). "Comunidad. En busca de seguridad en un mundo hostil”. Madrid, Siglo XXI BAUMAN Z.; C. BORDONI (2016). "Estado de crisis", Paidós, Barcelona. pp. 152.

BENITO, D. (2013). "Despoblación, desarraigo y escuela rural: condenados a encontrarse". Encrucijadas, Revista crítica de Ciencias Sociales, No. 6, pp. 56-69.

BOIX R. (2003). "Escuela rural y territorio: entre la desruralización y la cultura local". http:// educacion.upa.d/revistarural/erural.htm. Fecha de consulta: 06-09-2017. 
BURRIAL, X. et allii. (2008). "Mito y realidad de la escuela rural catalana”. En Llevot, N. y Garreta, J. (eds). (2008), Escuela rural y sociedad. Lleida: Edicions de la Universitat de Lleida, pp. 87-122. . (2007). "L'ecole rurale en Catalogne, présent et avenir" Colloque International Éducation et Territoires, Digne les Bains, 30-11-2007, Universidad de Provence, edición en CD.rom.

BUSTOS, A. (2008). "La escuela rural ante el contexto en transformación”. Revista de Educación", 350, pp. 449-461.

CAMARERO, L. (coord.) (2009). "La población rural de España. De los desequilibrios a la sostenibilidad social", Barcelona, Obra Social de La Caixa

CASASEMPERE (2011), Curso introductorio de análisis de datos cualitativos con Atlas.ti. Alcoy, Cualsoft.

CASTELLS, M. (1998). "La era de la información. El Poder de la Identidad". Vol. 2. Alianza Editorial, pp. 29-33.

CLOKE, P.; LITTLE, J. (1997). “Contested Countryside Cultures”. Londres, Routledge.

DÍAZ MÉNDEZ, C. (2005). Aproximaciones al arraigo y al desarraigo femenino en el medio rural: mujeres jóvenes en busca de una nueva identidad rural. Papers Revista de Sociología, 75, 2005, pp. 63-84.

DURU-BELLAT M.; VAN ZANTEN P. (1992). “Sociologie de l'école”, Armand Colin, París.

ENTRENA, F. (1998). "Viejas y nuevas imágenes sociales de la ruralidad". Estudios Sociales y Agricultura, 11, 1998, pp. 76-98.

. (2013). "Imaginarios de lo rural construidos por los urbanos". XI Congreso FES, Madrid 1012. Julio 2013, Grupo de trabajo de "Sociología Rural".

ESTALELLA, H.; CARRASCO, S. (1998). "La Catalunya rural contemporània”. En GINER, S. (edit). La societat catalana. Barcelona: Generalitat de Catalunya, IEC, pp. 367-376.

LITTLE, J.; AUSTIN P. (1996). "Women and the rural idyll". Journal of. Rural Studies, 12, pp. $101-111$

MATTHEWS H.; TAYLOR M.; SHERWOD K.; TUCKER F.; LIMB, M. (2000). "Growing-up in the contryside: children and the rural idyll”. Journal of. Rural Studies, 16 (2000). pp. 141-153.

MILES, M.B.; HUBERMAN, A. M. (19942/e), Qualitative Data Analysis: An Expanded Sourcebook. Londres, Sage Publications.

MUEL DREYFUS F. (1983). "Le mètier d'éducateur”,París, Mimmit.

MURDOCH, J.; J. PRATT, A. (1993), "Rural Studies: Modernism, Postmodernism and the Postrural”. Journal of Rural Studies. Vol. 9, No. 4.

NEWBY, H.; SEVILLA GUZMAN, E. (1983). "Introducción a la sociología rural". Alianza Universidad, Madrid.

SALA, T.; SAMPER, L; y BURRIAL, X. (2014). "Changing rural identity. Discourses on rurality in catalan schools" en SABATÉ, F. (ed.) "Identities on the move" Peter Lang, Bern, pp. 367-385.

SOLER, J. (2005). "L'escola rural a Catalunya al darrer quart del segle XX". Educació i Histórica. Revista d'Història de l'Educació". No 8, pp. 78-102.

STRAUSS A.; CORBIN J. (2002). Bases de la investigación cualitativa, técnicas y procedimientos para desarrollar teoría fundamentada. Editorial Universidad de Antioquia, Medellín.

SUBIRATS, M. (1983), "L'escola rural a Catalunya”. Barcelona: Rosa Sensat/Ed. 62.

TAYLOR, S.; BOGDAN, R. (1986). "Introducción a los métodos cualitativos de investigación". Buenos Aires, Paidós. 